\title{
Demographic Bonus for Indonesia: Challenges and Policy Implications of Promoting Universal Health Coverage
}

\author{
Sidayu Ariteja' \\ Ministry of National Development Planning/BAPPENAS
}

\begin{abstract}
Indonesia has been promoting Universal Health Coverage (UHC) since 2014 as targeted in the national development plan document. Indonesia has also entered the stage of demographic bonus that could enhance the benefit of social welfare. Starting from the idea of demographic bonus and the campaign of accelerating $\mathrm{UHC}$ in Indonesia, this paper tries to answer question of how demographic dividend affects the promotion of UHC declared by the government of Indonesia. Then, this paper analysis the effects of demographic bonus based on two specific policies, supply side policy and demand side policy. The results of the analysis might not directly relate to the issue of demographic bonus. However, it could recommend several suggestions which could deal with the opportunity of demographic bonus. This paper is limited as it only based on some simple calculations on meeting the needs and the gaps on UHC.
\end{abstract}

Keywords: Indonesia, Universal Health Coverage, and Demographic Bonus

The author is a Planner Staff at Directorate of Health and Community Nutrition, Ministry of National Development Planning/ Bappenas. Email address: sidayu.ariteja@bappenas.go.id 


\section{Introduction}

Indonesia has been promoting Universal Health Coverage (UHC) since 2014 After enacting Law No.40/2004 on National Social Security System, the government of Indonesia expects that there would be a full UHC by 2019. As targeted on Mediumterm National Development Plan 2015-2019 document, the first step was an establishment of a special agency which is responsible for conducting an integrated national health insurance (named as BPJS Kesehatan) in January 2014. However, several challenges have been faced by governments (central and local governments). Firstly, there is double-burden problem in providing health care facility. In total number, there are challenges to develop the health care infrastructure nationwide. There are also development gaps and inequalities in providing health care facility: between urban-rural areas, western-eastern part regions, and Java island-nonJava islands. Secondly, in the view of national health insurance memberships, the government has to conduct a proper policy to increase the citizen's awareness for joining the program, especially in informal sectors. Based on the data, the percentage of national memberships of national health insurance was still 71.25 per cent, equal to more than 186 million people 2 . From that rate, most of them which are equal to 92.3 million people (49.4 per cent) was fully subsidized by the government in paying the special premium since they belong to the social-assistance recipients program.

Several demographic experts say that Indonesia has been entering a phase that is called "demographic bonus" (or "demographic dividend"). This population's changing age structure could be a catalyst to boost economic growth as well as enhance social welfare. Demographic bonus would open a" window of opportunity" which sometimes might start to close $^{3}$. This stage might bring benefit for the country. In the federal system nations like the United States (US) and Brazil, this circumstance decreased the burden of funding for state and local governments ${ }^{4}$. Lee and Mason (2011) said that in many economies that have experienced demographic dividend, funding of public education has been maintained or increased by allowing expanded enrollment and increased investment per student. Giving a further example, the demographic bonus effect on the post-war Japanese economy was essential for boosting their remarkable economic growth ${ }^{5}$. For China, the labor force that continually increased because of high fertility rate combined with the decline of mortality lead to demographic dividend, but favorable age structure could not guarantee the "harvest" of demographic dividend. It had to be combined with other factors ${ }^{6}$. Based on the arguments above, Indonesia needs to be able to convert this window opportunity into real benefits, not letting it changes into opportunity cost.

Demographic bonus might has benefit to the promotion of UHC in Indonesia. A young population structure might provide favorable effects for establishing UHC, because it could minimize the transfer of income from the young people to the

\footnotetext{
Based on data from BPJS Kesehatan, as 1 December 2017

Hayes, A., D. Setyonaluri. 2015. "Taking Advantage of the Demographic Dividend in Indonesia: A Brief Introduction to Theory and Practice". UNFPA.

Lee, R., A. Mason. 2011. "Population Aging and Generational Economy: A Global Perspective". Edward Elgar Publishing Limited.

Ogawa, N., M. Kondo and R. Matsukura. 2005. "Japan's Transition from the Demographic Bonus to Demographic Onus". Asian Population Studies, 1:2, 207-226, DOI: 10.1080/17441730500317451.

Peng, X., C. Yuan. 2005. "Harvesting the Demographic Bonus". Asian Population Studies, 1:2, 189-205, DOI. $10.1080 / 17441730500317329$
} 
elderly people through social security program conducted by the government ${ }^{7}$. In addition, because of the pension program would not matured yet as well as a low portion expenditure of health care for elderly, the government might tend to have more fiscal space to provide a proper resources to enhance their UHC. Like other developing countries, Indonesia has limited government budget since they need to develop the other fundamental aspects like infrastructures which need a lot of resource allocations. Thus, the favorable fiscal space affected by "demographic dividend" could be beneficial for the government, in terms of UHC program. In case of Indonesia, the government has to fully finance (paying the premium) of population identified as social-assistance recipient groups which contain of poor people and other economically minority groups. On the other hand, the government also faces the problems of unequal development in health sector which affect the campaign of UHC. Development inequalities in health sector have become one of major challenges for central and local governments in recent years. These inequalities could be between western-eastern parts of Indonesia as well as urbanrural areas, and happened in developing health care infrastructures with its health human resources.

Starting from the idea of demographic bonus and the campaign of accelerating $\mathrm{UHC}$ in Indonesia, this paper would try to answer the question of how demographic dividend affects the promotion of UHC declared by the government of Indonesia. Looking at the main purpose of the paper, this paper would analysis the effects based on two specific policies, supply side policy and demand side policy. On one perspective, supply side policy means analyzing effects of demographic bonus on how the government provides the health care infrastructures. On the other view, demand side policy means observing the effects of demographic bonus on how the government finance the premium of the national health insurance. The limitation of this paper is that the analysis of the paper was only be based on the simple calculation on meeting the needs and the gaps on UHC and particular indicators of health care infrastructure in order to react with the issue of demographic dividend in the view of government budgeting. The analysis was mainly be based on the official data provided by the government, such as official population projection and health profile of Indonesia.

\section{Literature Review: Demographic Bonus}

Indonesia is a home for more than 237 million $^{8}$ people, making this country presently the fourth most populous country in the world after China, India, and the US. According to the population projection by the UN, Indonesia would be eighth in the list of countries contributing to the population growth by 2050 . According to the opinion of several experts, because of the successful past policy that made the fertility and mortality rates decrease, today Indonesia's population structure has 28 per cent population aged below 15 years old, 8 per cent people aged 60 years old and more, and 64 per cent population aged between 15 and 60 years old ${ }^{9}$. The composition of age is meant as "demographic bonus". Figure 1 shows the age structure of Indonesia's population in 2010 and 2015 based on 2010 Population Census.

\footnotetext{
Oshio T. et.al. 2015. "The Economic Impact and Challenges of Universal Health Coverage in Japan". Global Health Working Group for the 2016 G7 Summit, December 2015.

8 Based on the 2010 Population Census.

9 Based on the 2010 Population Census.
} 
Figure 1. Indonesia's Population Pyramid, 2010 and 2015
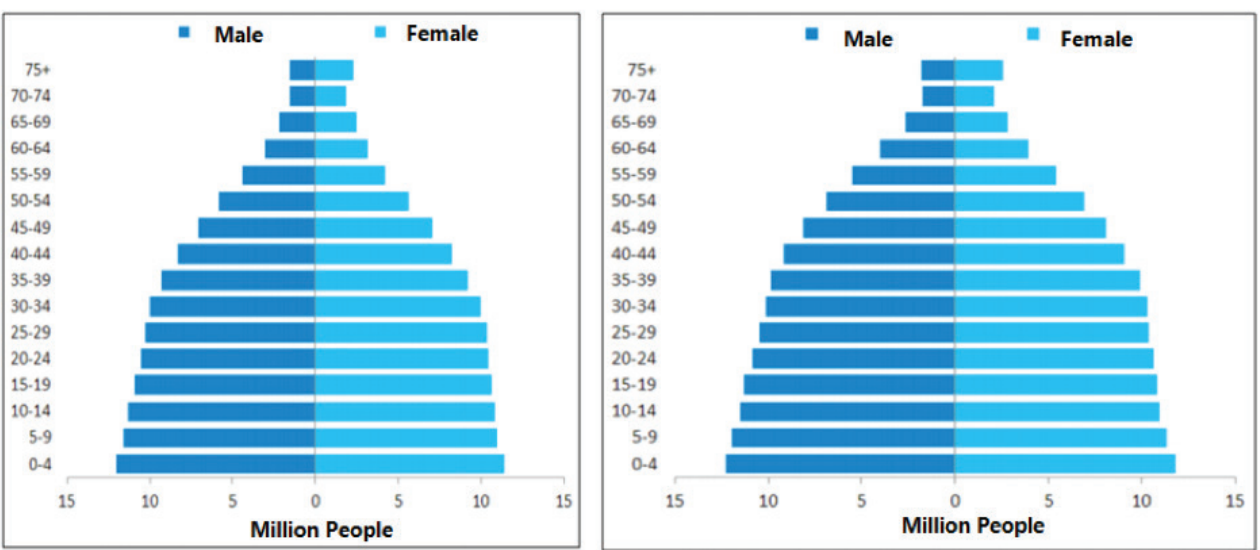

Source: the Indonesia Population Census 2010 and Official Population Projection based on Population Census 2010

One of possible explanation about the reason of demographic dividend is that the declining of total fertility rate (TFR) because of increasing trend of contraceptive prevalence rate (CPR). Figure 2 describes the relationship between TFR and CPR. Based on the particular data, at least, it might be assumed that there is a negative relationship between TFR and CPR. It could be possible because the growing use of contraceptive tools might decrease the fertility rate. It might be caused by an obligatory policy about family planning in the past. It was well known as "2-Child Family Norm" (in Indonesian language, "2 anak cukup") program. Since the establishment of the official family planning board, which is a direct responsible to the President, in 1971, Indonesia had have a special institution that coordinates and manages family planning program in all sectors in order to control the fertility rate. Although it had much more power during Soeharto's administration (1965-1998) because it had integrated family planning policy including a proper budgeting allocation, now this institution (named as National Coordinating Agency for Family Planning or BKKBN) still has the function of coordinating family planning program that might maintain TFR.

Figure 2. Total Fertility Rate (TFR) and Contraceptive Prevalence Rate (CPR), $1991-2012$

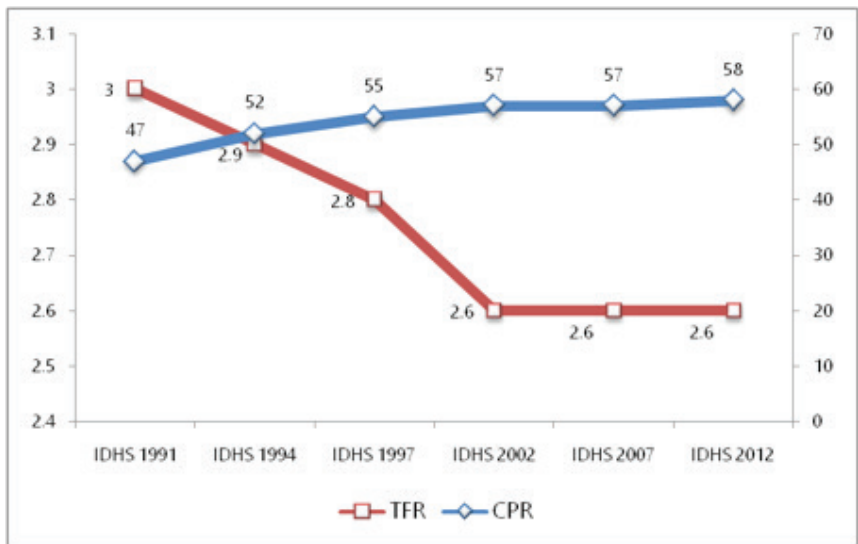

Source: Central Agency for Statistics of Republic of Indonesia, accessed in February 2017 
As a result, the dependency ratio would have a downward trend, and after 2011, "the window of opportunity" would open. As described in Figure 3, the lowest dependency ratios period would come between 2028 and 2031. Then, the upward trend would come after 2033 until "the window of opportunity" would close. This figure is based on the official population projection released by the government in 2013, which is projected using the Population Census in 2010.

Figure 3. Population Projection by Age and Dependency Ratio, 2010 - 2035

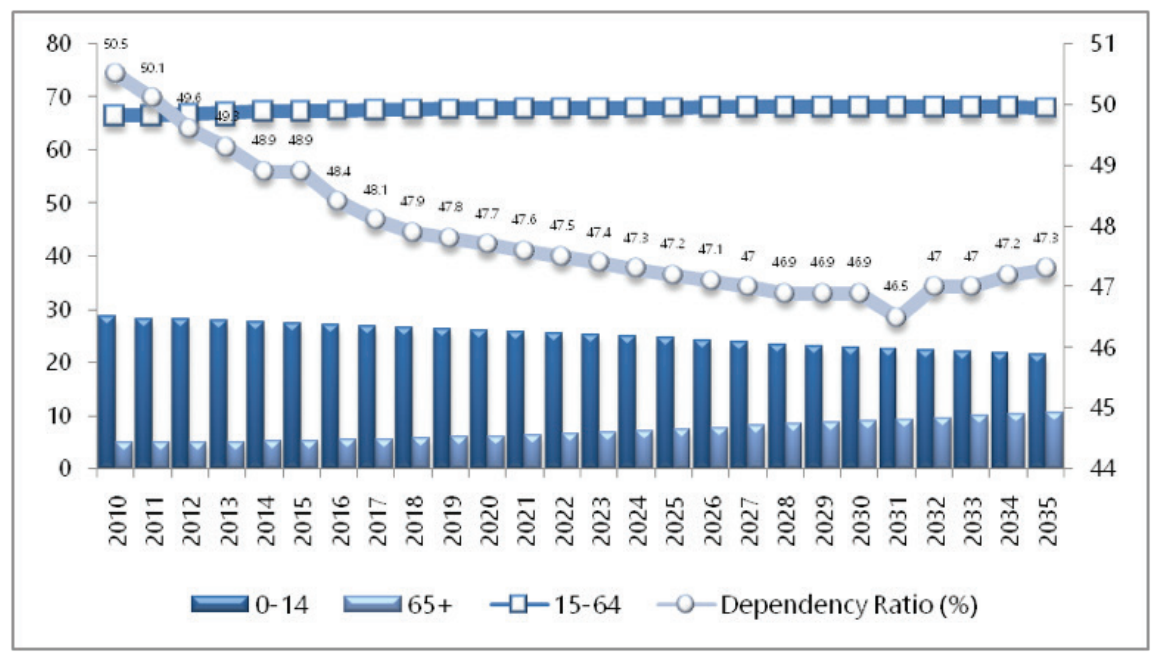

Source: the Indonesia Population Projection 2010 - 2035, 2013

\section{Methodology: Demographic Bonus and the Promotion of Universal Health Coverage}

Correlating to the government program which is enhancing national health insurance to promote UHC, demographic bonus could be an interesting issue to be observed. In one way, it could be a good opportunity for the government since most of the people are in working age. It is paramount to increase the memberships of national health insurance (NHI) because it is targeted that 95 per cent of the population have to be covered by $\mathrm{NHI}$ by $2019^{10}$. In the other way, there could be a challenge for the government since the higher portion of working age means there would be more people that need social-assistance premium from the government ${ }^{11}$. Another issue is about the inequalities in health care facilities supporting $\mathrm{NHI}$. Of course, the availabilities of the health care facilities could be an essential factor to promote UHC.

Considering several factors above, the analysis would be classified into two sides: demand side and supply side. This analysis emphasizes on the perspective of government budgeting, so it would not cover the observation of membership issue that categorized as self-financed members. Figure 4 shows the framework of the analysis.

\footnotetext{
${ }^{10}$ Based on Medium-term National Development Plan of 2015 - 2019.

$"$ National Health Insurance (NHI) program in Indonesia is divided into 2 types of premium, fully-financed by the government and self-financed. In case of fully-financed class, the government would pay the premium of the people included as socialassistance recipient (in Indonesian language, "Penerima Bantuan luran"). This targeted people would be assigned by the government.
} 


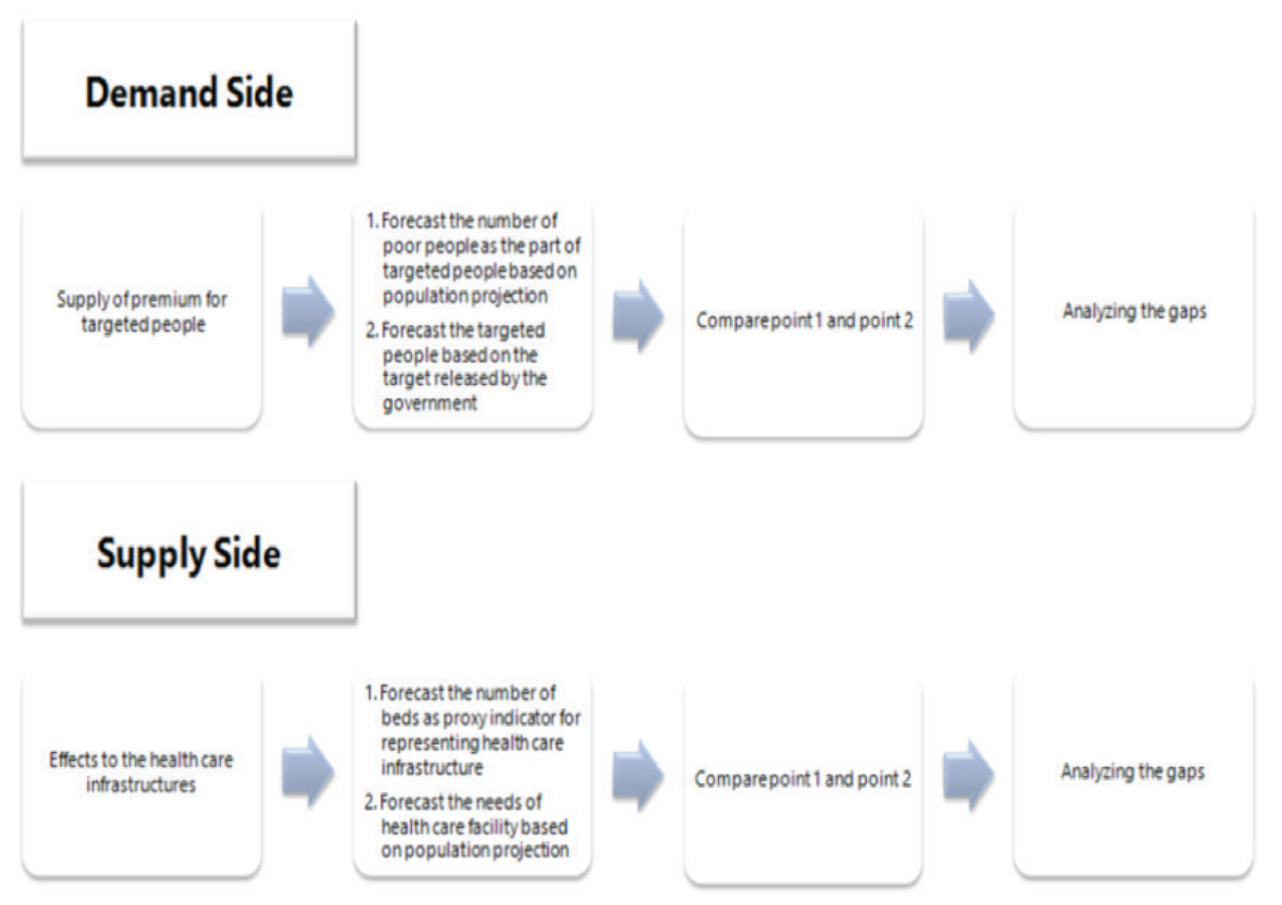

However, this analysis would be based on several scenarios and assumptions. In case of demand side, the scenarios would be divided into three types: no-growth scenario ${ }^{12}$, upward growth scenario ${ }^{13}$, and downward growth scenario ${ }^{14}$. For the supply side, there would be three scenarios as well: no-growth scenario ${ }^{15}$, ordinary growth scenario ${ }^{16}$, and optimistic growth ${ }^{17}$. The first assumption applied in the analysis is that there is no huge economic shocks that might significantly influence the government budget. The second assumption is that analysis would be applied every five years for considering the cohort. Last assumption is that the poverty rate would be projected as the value in whole population, it would not be specified based

12 No-growth scenario means that the percentage would be the same as the nearest year. For forecasting the number of poor people, 10.7 per cent is used in the analysis because this ratio represents the ratio of 2016 (nearest observed data). For forecasting the targeted people (PBI), 40 per cent is used in the analysis because this percentage represents the target which is observed by the government (Bappenas) to achieve the target of NHI memberships of 2019.

13 Upward-growth scenario means that there would be an increased trend of particular observations. For forecasting the number of poor people, 1 per cent per 5 years is used in the analysis because this ratio represents the average difference of the number of poor people in the last 5 years $(2011$ - 2016). For forecasting the targeted people (PBI), 5 per cent per 5 years is used in the analysis since this percentage represents the average of difference of the number PBI covered estimating by the government to reach the target in 2019 (95 per cent of memberships).

${ }_{14}$ Downward-growth scenario means that there would a decreased trend of particular observations. The percentage that would be used is the same with upward-growth scenario.

15 No-growth scenario means that the number of beds ratio and the health human resources ratio would be the same with the nearest data (2015). For forecasting the number of beds ratio, the ratio of 1.21 beds per 1,000 population is used because this ratio represents the ratio of the nearest data (2015). Using the same data of 2015, the number of doctors and nurses assumed that it would be the same with 2015

${ }^{16}$ Ordinary growth scenario means that there would be a similar increased trend of particular observations with the last 5 years data. For the number of beds ratio growth, it would use 1 per cent per 5 years since it was average growth in last 5 years (2010 - 2015). For the number of health human resources, it would use the same assumption of number of beds ratio, which is 2.5 per cent per year.

${ }^{17}$ Optimistic growth scenario is simple based on the realistic assumption of the author. For number of beds ratio growth would be used the growth of 5 per cent every 5 years. For the number of health human resources, it would use a very optimistic value, which is 10 per cent per year. 
on age structure ${ }^{18}$. The limitation of the analysis is that there is no analysis about inequalities among provinces (sub-national), especially in the supply side analysis.

\section{Analysis}

\subsection{Demand Side}

Table 1 shows the result of gap analysis between the forecast of the number of poor people and the forecast of the number of targeted people. Targeted people contains of poor people and other minority groups in the society requiring financial supports from the government to pay the premium of NHI. Thus, the poor people are the main part of targeted people. Because of that reason, it is important to forecast the number of poor people to guarantee the coverage of government program.

Table 1. The Results of Gap Analysis of Demand Side

\begin{tabular}{|l|c|c|c|c|}
\hline Year & $\mathbf{2 0 2 0}$ & $\mathbf{2 0 2 5}$ & $\mathbf{2 0 3 0}$ & $\mathbf{2 0 3 5}$ \\
\hline $\begin{array}{l}\text { No-growth Scenario (in thousand } \\
\text { people) }\end{array}$ & $29,004.10$ & $30,476.70$ & $31,715.35$ & $32,704.81$ \\
\hline $\begin{array}{l}\text { Upward Growth Scenario (in } \\
\text { thousand people) }\end{array}$ & $29,004.10$ & $33,324.99$ & $37,643.45$ & $41,874.38$ \\
\hline $\begin{array}{l}\text { Downward Growth Scenario (in } \\
\text { thousand people) }\end{array}$ & $29,004.10$ & $27,628.41$ & $25,787.24$ & $23,535.23$ \\
\hline
\end{tabular}

Based on table above, the forecast says that the government has ability to cover number of poor people as the part of targeted people in all scenarios. There might be a bigger space for government in order to cover the minority groups. In this demand side, there would be no burden for the government to promote UHC. Relating to the demographic bonus, there might be no direct correlation regarding to covering the poor people since the government assigns the target does not based on the age structure, but it is based on poverty line.

Although there might be no burden for the government to cover the premium for poor people, there is still challenge for the government, relating to the demographic bonus. As there is a big portion of working age in the population, there might be a lot of potential in increasing the memberships of self-financed premium. As developing nation, most of workers in Indonesia work in informal sector that might not have awareness to join the $\mathrm{NHI}$.

\subsection{Supply Side}

Table 2 describes the results of gap analysis between needs ${ }^{19}$ and forecast of the number of beds ratio 20 in Indonesia. Based on the analysis, there are no spaces for the government in all scenarios to fulfill the needs of people. It could be argued that since there were a lot of priorities for the government in funding the developments, the government could not fully focus on enhancing the health care facilities. As the result, there were a lot of gaps in health care infrastructures. In the other words, there is a burden of government in term of budgeting allocations.

\footnotetext{
${ }^{18}$ This assumption is based on the government policy that the number of poor people as well as targeted people (PBI) is officially assigned by the government. This value is based on the whole population, it does not represent age structure of the population.

${ }_{19}$ The needs are based on the ratio of average OECD countries in 2013 because there is no clear standard of the ratio of number of beds from World Health Organization (WHO).

${ }^{20}$ The number of beds ratio per 1,000 people is used as the proxy of health care infrastructures. It could be used as proxy since the number of beds might represent the readiness indicator of the supply side in order to support $\mathrm{NHI}$.
} 
Table 2. The Results of Gap Analysis of the Number of Beds Ratio

\begin{tabular}{|l|c|c|c|c|}
\hline Year & $\mathbf{2 0 2 0}$ & $\mathbf{2 0 2 5}$ & $\mathbf{2 0 3 0}$ & $\mathbf{2 0 3 5}$ \\
\hline No-growth Scenario & $(1,027,341.66)$ & $(1,096,154.66)$ & $(1,154,035.16)$ & $(1,200,271.66)$ \\
\hline $\begin{array}{l}\text { Ordinary Growth } \\
\text { Scenario }\end{array}$ & $(1,024,061.75)$ & $(1,089,562.05)$ & $(1,144,096.72)$ & $(1,186,953.93)$ \\
\hline $\begin{array}{l}\text { Optimistic Growth } \\
\text { Scenario }\end{array}$ & $(1,010,942.14)$ & $(1,062,535.65)$ & $(1,102,335.68)$ & $(1,129,587.69)$ \\
\hline
\end{tabular}

Similarly, there would be also gaps for the government to provide health workforces. In this case, this paper examines the ratio of doctors and nurses (per 1,000 people). Table 3 shows the results of gap analysis on health human resources. There would be many gaps (all the values are minus) in all scenarios to fulfill the proper standard. The limited budget allocations could be one of the reasons. In addition, the inequalities in providing health workforces of local government might also be other reasons. After Indonesia transformed to decentralization system in $2001^{21}$, there are a lot of problems regarding to health human resources distribution. It might lead to the ratio in general term.

Table 3. The Results of Gap Analysis of the Health Human Resource Ratios

\begin{tabular}{|l|r|r|r|r|}
\hline Year & \multicolumn{1}{|c|}{$\mathbf{2 0 2 0}$} & \multicolumn{1}{c|}{$\mathbf{2 0 2 5}$} & \multicolumn{1}{c|}{$\mathbf{2 0 3 0}$} & \multicolumn{1}{c|}{$\mathbf{2 0 3 5}$} \\
\hline No-growth Scenario & & & & \\
\hline Doctors & $(805,644.12)$ & $(851,060.70)$ & $(889,261.83)$ & $(919,777.92)$ \\
\hline Nurses & $(2,242,794.24)$ & $(2,368,033.90)$ & $(2,473,376.41)$ & $(2,557,526.84)$ \\
\hline $\begin{array}{l}\text { Ordinary Growth } \\
\text { Scenario }\end{array}$ & & & & \\
\hline Doctors & $(794,534.75)$ & $(827,453.28)$ & $(851,594.11)$ & $(866,292.35)$ \\
\hline Nurses & $(2,214,805.49)$ & $(2,308,557.81)$ & $(2,378,477.05)$ & $(2,422,776.32)$ \\
\hline $\begin{array}{l}\text { Optimistic Growth } \\
\text { Scenario }\end{array}$ & & & & \\
\hline Doctors & $(761,206.62)$ & $(739,966.95)$ & $(678,183.71)$ & $(558,723.23)$ \\
\hline Nurses & $(2,130,839.24)$ & $(2,088,146.40)$ & $(1,941,590.16)$ & $1,647,892.47)$ \\
\hline
\end{tabular}

\section{Conclusions and Recommendation}

\subsection{Conclusions}

Demographic bonus could bring advantages or disadvantages for the government relating to the promotion of universal health coverage (UHC). The big portion of workforces might lead to the increase of financial ability of the government through enhancing the economic effects. On the other hand, it might push the government budget by increasing number of targeted people which its premiums are fully financed by the government.

The results of the analysis do not directly relate to the opportunity of demographic dividend since the characteristic of the national health insurance $(\mathrm{NHI})$ is quietly different with the other NHIs. In the perspective of demand side, the government would be able to cover the premium of poor people. Because of the targeted people is assigned by a specific calculation, there is no direct relationship with the demographic dividend. In the perspective of supply side, there are a lot of gaps in proving health care infrastructures as well as health workforces. It might be similar with the demand side that there is no direct effects of demographic

\footnotetext{
${ }^{21}$ Based on Law No.32/2004 about Local Government.
} 
dividend on the health care infrastructures and health workforces in the view of government budgeting.

However, there several recommendations that could be suggested to affect the promotion of UHC relating to the demographic bonus. In case of demand side, it is essential for government to develop a perfect campaign in order to boost the memberships of self-financed premium. On the supply side, developing mutual relationships with the private sector and building a proper strategy to persuade the workforces to become health human resources could be possible recommendations.

\subsection{Policy Recommendations}

Based on analyses presented above, we recommend:

1. It is essential for the government to much more focus on the self-financed premium. This thanks to a lot of young working age people contributed by the demographic dividend.

2. It is important for the government to develop a proper campaign strategy in order to enhance the self-finance memberships of $\mathrm{NHI}$ facing the window of opportunity.

3. Persuade private sectors to fulfill the gaps of health infrastructure. This is due to wide gaps between health care infrastructures and health workforces, and because of the growing ability of the private sectors in providing such services.

4. Develop a perfect policy to persuade the benefit of abundant workforce resources for being health workers, for example by providing scholarships or incentives to young people to fulfill the gaps of health workforces in remote areas. 


\section{References}

Social Security Administrator for Health of Republic Indonesia. 2017. Memberships of $\mathrm{NHI}$.

Central Agency for Statistics of Republic Indonesia. 2012. Indonesia Population Census 2010.

Central Agency for Statistics of Republic Indonesia et.al. 2013. Indonesia Population Projection 2010 - 2035.

Hayes, A., D. Setyonaluri. 2015. Taking Advantage of the Demographic Dividend in Indonesia: A Brief Introduction to Theory and Practice. United Nation Population Fund.

Lee, R., A. Mason. 2011. Population Aging and Generational Economy: A Global Perspective. Edward Elgar Publishing Limited.

Ministry of Health of Republic Indonesia. 2016. Indonesia Health Profile of 2015.

Ministry of National Development Planning/Bappenas. 2014. Indonesia Medium term National Development Plan of 2015 - 2019.

Ogawa, N., M. Kondo and R. Matsukura. 2005. Japan's Transition from the Demographic Bonus to Demographic Onus. Asian Population Studies, 1:2, 207-226, DOI: 10.1080/17441730500317451.

Oshio T. et.al. 2015. The Economic Impact and Challenges of Universal Health Coverage in Japan. Global Health Working Group for the 2016 G7 Summit, December 2015.

Peng, X., C. Yuan. 2005. Harvesting the Demographic Bonus. Asian Population Studies, 1:2, 189-205, DOI: 10.1080/17441730500317329. 